\title{
Article \\ Influence of Surface Pretreatments on the Anticorrosion of Polypyrrole Electro-Polymerized Coatings for Copper in Artificial Seawater
}

\author{
Hetao Zhu ${ }^{1}$, Xiaoyan Liu ${ }^{1}$, Hua Hao ${ }^{2, *}$ and Xingwen Zheng ${ }^{3}$ \\ 1 College of Chemistry and Materials Engineering, Beijing Technology and Business University, \\ Beijing 100048, China; zhuht111@163.com (H.Z.); $12509701563 @ 126 . c o m$ (X.L.) \\ 2 Institute of Chemistry, Chinese Academy of Sciences, Beijing 100190, China \\ 3 Key Laboratory of Material Corrosion and Protection of Sichuan Province, Sichuan University of Science \& \\ Engineering, Zigong 643000, China; zxwasd@126.com \\ * Correspondence: haohuaiccas@126.com
}

check for updates

Citation: Zhu, H.; Liu, X.; Hao, H.;

Zheng, X. Influence of Surface

Pretreatments on the Anticorrosion of

Polypyrrole Electro-Polymerized

Coatings for Copper in Artificial

Seawater. Metals 2022, 12, 383.

https://doi.org/10.3390/

met12030383

Academic Editors: Sebastian Feliú, Jr. and Alexandre Emelyanenko

Received: 13 January 2022

Accepted: 18 February 2022

Published: 23 February 2022

Publisher's Note: MDPI stays neutral with regard to jurisdictional claims in published maps and institutional affiliations.

Copyright: () 2022 by the authors. Licensee MDPI, Basel, Switzerland. This article is an open access article distributed under the terms and conditions of the Creative Commons Attribution (CC BY) license (https:/ / creativecommons.org/licenses/by/ $4.0 /)$.

\begin{abstract}
Plasma discharging treatment (hydroxylation) was conducted on copper surfaces for the subsequent electro-polymerization procedure of polypyrrole (PPy) coating (d-PPy). The hydroxylated surface could solve the criticized adhesion strength and protection efficiency of electropolymerized coatings for metal substrate in corrosive media. Compared with the counterpart obtained via passivation pretreatment ( $\mathrm{p}-\mathrm{PPy}$ ), a well-adhered d-PPy layer was acquired on the hydroxylated copper surface, which earned a satisfactory adhesion grade, compactness and conductivity. Appreciable protection of d-PPy was measured for copper in the artificial seawater (ASW) at $298 \mathrm{~K}$ via electrochemical and surface analyses. Results of electrochemical measurements indicated that d-PPy coating effectively retarded copper corrosion in ASW with a lowered corrosion current density and improved charge transfer resistance. Surface analysis revealed that the typical morphology of PPy was retained after $240 \mathrm{~h}$ immersion in ASW. A favorable physical barrier and anodic protection efficacy might account for the superior protection of d-PPy coating for the underlying copper. Molecular dynamics simulations for the deposition of PPy chains on pristine and hydroxylated copper planes provided a definite correlation between the theoretical calculations and experimental observations. Theoretical modelling also disclosed in-depth the anchoring nature and anticorrosive mechanism for PPy toward the hydroxylated copper in ASW.
\end{abstract}

Keywords: polypyrrole; electro-polymerization; plasma discharge; coating; corrosion inhibition; molecular dynamics simulation

\section{Introduction}

Economic loss caused by metal corrosion has exceeded four trillion dollars per year all over the world, which is roughly equal to $30 \%$ of global steel production [1]. Of this, the corrosion of facilities, watercrafts and communicating equipment in marine environments occupies the dominant portion in the total metallic damage [2-4]. For instance, copper and its alloys are frequently utilized as the structural materials in ships and coastal infrastructures due to their excellent electronic/heat conductivity, favorable ductility and shiny appearance. However, rapid deterioration of copper inevitably occurs in the marine atmospheric environment or seawater [5]. Therefore, persistent endeavors have been dedicated to efficient solutions for retarding or mitigating copper corrosion in the marine ambient. Structural design and optimization, electrochemical protection, using corrosion inhibitors and employing protective coatings constitute the main strategies of protecting metals from corrosive attack [6-8]. Among all the anticorrosive routes, the utilization of coatings is deemed one of the most effective methods to impede corrosion of the underlying substrates in aggressive media. 
Recently, much attention has been paid to conducting polymers (CPs) as protective coatings for the tunable conductivity, anodic protection capacity and interfacial electronmediating effect [9]. In particular, CPs can be rapidly prepared via electrochemical deposition on the substrate (i.e., electro-polymerization) from $\pi$-conjugated monomers such as pyrrole, aniline and thiophene [10]. A literature survey also reveals that electro-polymerization is a promising alternative for the in-situ formation of anticorrosive coatings due to the cost-effective raw monomers, environmental stability, superior mechanical properties and redox reversibility. Among various electroactive compounds, pyrrole is one of the most sought-after monomers to fabricate CPs (polypyrrole, PPy) [11]. Menkuer et al. [12] electrodeposited PPy $/ \mathrm{ZrO}_{2}$ composite coatings in oxalic acid and dodecylbenzene sulfonic acid mixed electrolyte, which exhibited almost $100 \%$ protection efficiency for aluminum in $0.1 \mathrm{M} \mathrm{HCl}$ solution. Nascimento and co-workers [13] fabricated PPy coatings on stainless steel by cyclic voltammetry $(\mathrm{CV})$ and correlated the relationship between chemical states of PPy and its protection performance for the substrate in phosphate-buffered saline solution. They found that the corrosion resistance of as-synthesized PPy coatings increased with the reduction in the doping level. Chen et al. [14] employed V-modified $\mathrm{TiO}_{2}$ as the dopant to form the p-n junction with the PPy layer on mild steel surface, which could effectively retard metal corrosion in $0.1 \mathrm{M} \mathrm{HCl}$ solution by virtue of its anodic protection ability and the barrier effect. However, owing to the polarity difference between the organic polymer and the metal surface, the adhesion strength of electro-polymerized resultants on the substrates still challenges their practical application. For remediation, a passivation procedure is compulsory for the substrate (e.g., copper) before the polymerization process, which can provide a relatively stable surface for the subsequent deposition of CPs [15]. Although depositing on the passivated surface, the compactness and adhesion grade of PPy coatings over copper surfaces hardly conform to the requirements of feasible protection performance for the substrate underneath [11]. Thus, exploring an efficient alternative overmatching the conventional passivation is of particular value for the preparation of strong, anchored PPy coating through electrochemical strategy. In addition, methods other than surface passivation of metals for the favorable deposition and anticorrosive efficacy of CPs are rarely studied.

Plasma discharging can equip the metal surface, such as copper, with abundant hydroxyl groups, which further improves the affinity of the electrode surface toward the ambient electrolyte due to the enhanced interfacial polarity. Moreover, the surface energy of plasma-discharged copper is hugely elevated, favoring the accommodation of electropolymerized resultants [16]. Although the lifespan of grafted hydroxyl is temporary (from several hours to days), it is sufficient to electrochemically fabricate PPy coatings. Surface hydroxylation also provides active centers on the copper surface to interact with the polymer backbone during deposition through combined forms, such as covalent bonds, electrostatic interaction and hydrogen bonds [17].

On that account, plasma discharging was employed in this work for the pre-treatment of copper surface before pyrrole polymerization, as shown in Scheme 1. The strong adhesion force and conductivity of the as-prepared PPy layer was verified by physical characterizations. Principally, the favorable anticorrosion capability of as-prepared coating was evaluated through potentiodynamic polarization, electrochemical frequency modulation (EFM) and impedance spectroscopy (EIS) for copper in the artificial seawater (ASW). Surface wettability and morphology were also examined to consolidate the protection effect of PPy coating deposited on the hydroxylated copper surface. Furthermore, molecular dynamics (MD) simulations were performed to deeply clarify the strong adhesive nature and excellent anticorrosion mechanism of PPy coating on copper surface after plasma discharging. Prospectively, owing to convenience, efficiency and cost-effectiveness, in-situ electro-polymerized CPs on hydroxylation-treated metal surfaces may be a unique solution for preventing and repairing copper-based components in ships from severe corrosion in marine environments. 


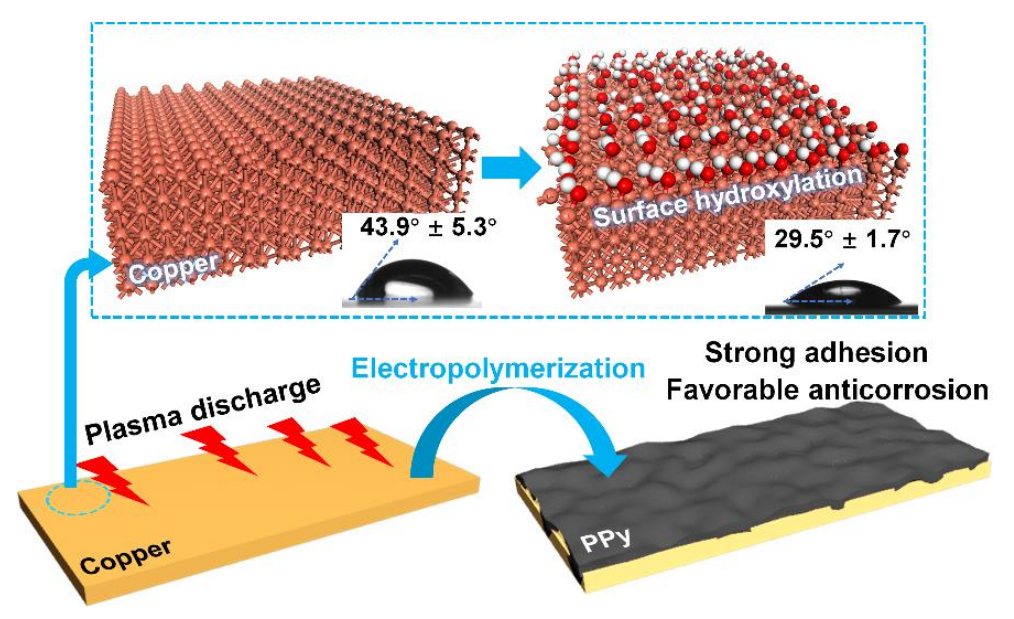

Scheme 1. Schematic diagram for the preparation of d-PPy coating on a copper surface with strongly adhesive and anticorrosive characteristics.

\section{Materials and Methods}

\subsection{Raw Materials and Solutions}

All used chemicals were analytically pure except as detailed in the additional illustration. Pyrrole, anhydrous oxalic acid and ethanol were obtained from Aladdin Reagent Co., LTD (Shanghai, China). Notably, pyrrole was bi-distilled and stored at $276 \mathrm{~K}$ in the dark before utilization. The corrosive medium (ASW) was prepared by dissolving the listed salts (Table 1, Beijing Chemical Works, Beijing, China) in lab-purified deionized water. Pure copper sheets (T3 grade, $12 \times 12 \times 2 \mathrm{~mm}^{3}$ ) were supplied from Aida Company (Tianjin, China), and successively abraded with $\mathrm{SiC}$ paper from 400 to 2000 mesh, rinsed alternately with deionized water and absolute ethanol for about $10 \mathrm{~min}$, and stored in a vacuum desiccator. The supporting electrolyte for the formation of PPy coating contained $0.3 \mathrm{M}$ oxalic acid and $0.1 \mathrm{M}$ pyrrole in deionized water.

Table 1. Components in ASW as per the description in ASTM D1141-98 (2013).

\begin{tabular}{ccccccccccc}
\hline Compound & $\mathrm{NaCl}$ & $\mathrm{MgCl}_{2}$ & $\mathrm{Na}_{2} \mathrm{SO}_{4}$ & $\mathrm{CaCl}_{2}$ & $\mathrm{KCl}$ & $\mathrm{NaHCO}_{3}$ & $\mathrm{KBr}$ & $\mathrm{H}_{3} \mathrm{BO}_{3}$ & $\mathrm{SrCl}_{2}$ & $\mathrm{NaF}$ \\
\hline Content (g/L) & 24.53 & 5.20 & 4.09 & 1.16 & 0.695 & 0.201 & 0.101 & 0.027 & 0.025 & 0.003 \\
\hline
\end{tabular}

\subsection{Electrosynthesis of Different PPy Coatings}

Electrochemical assays were fulfilled in a three-electrode cell via a PGSTAT302N workstation (Metrohm, Herisau, Switzerland) at $298 \mathrm{~K}$. Copper (effective area: $1 \mathrm{~cm}^{2}$ ), $\mathrm{Ag} / \mathrm{AgCl}$ and $\mathrm{Pt}$ sheet electrodes served as working, reference and counter electrodes, respectively. Prior to electrosynthesis, different treatments were performed toward the copper surface. A passivation procedure of the copper surface in a monomer-free oxalic acid solution $(0.3 \mathrm{M})$ followed a known protocol based on $\mathrm{CV}$ in a potential range from -0.5 to $1.4 \mathrm{~V}$ (vs. $\mathrm{Ag} / \mathrm{AgCl}$ ) at $20 \mathrm{mV} / \mathrm{s}$ with three scans [15]. Another aspect, hydroxylation of the copper surface, was realized via a PDC-002 Plasma Cleaner (Harrick Plasma, Ithaca, NY, USA) in a quartz vacuum chamber with medium discharging strength (i.e., $10 \mathrm{kV}$ ) for $60 \mathrm{~s}$. Afterwards, the treated copper electrode was settled in argon ambient until the initiation of electro-polymerization.

The preparation of PPy coatings on passivated and hydroxylated copper surfaces was achieved by multiple $\mathrm{CV}$ scans in a potential range of $-0.5-1.1 \mathrm{~V}$ with a scan rate of $30 \mathrm{mV} / \mathrm{s}$. To avoid side reactions during PPy deposition, 20 cycles were controlled as the maximum scanning number. Preferentially, the supporting electrolyte was continuously purged with argon current throughout the polymerization course to remove unexpected oxygen. PPy coatings deposited on the passivated and hydroxylated copper surfaces were labeled as p-PPy and d-PPy, respectively. 


\subsection{Characterization of PPy Coatings}

Surface morphology was examined through a Quanta FEG 250 scanning electron microscope (SEM, FEI, Hillsboro, OR, USA) operating at $20 \mathrm{kV}$ of voltage and $700 \mathrm{nA}$ of current, which was equipped with an OCTANE PRIME energy dispersive X-ray spectroscopy (EDS, AMETEK Inc., Berwyn, PA, USA). Before SEM observation, all the samples were sprayed with a thin gold layer. The coating thickness was gauged by a digital micrometer (Jingco Co., LTD, Shanghai, China), and the reported value was the average result of five measurements on different coating spots. Attenuated total reflection Fourier transform infrared spectra (ATR-FTIR) were recorded by an iN10 MX model (Thermo Scientific, Waltham, MA, USA) in a wavenumber from 4000 to $500 \mathrm{~cm}^{-1}$ utilizing a ZnSe wafer as the probe. The electronic conductivity of the coatings was determined by a four-point collinear probe (Jingge Scientific, Hangzhou, China) via the standard protocol under the atmospheric environment [3]. The surface wettability of coated specimens before and after immersion in ASW was captured by an OCA35 optical goniometer (Dataphysics, Filderstadt, Germany) through the sessile drop ( $20 \mu \mathrm{L}$ of step drop) method at $298 \mathrm{~K}$ with a humidity of $33 \pm 2 \%$.

\subsection{Anticorrosive Evaluation for PPy Coatings}

As a matter of priority, the working electrode was conditioned in ASW for at least $1 \mathrm{~h}$ to stabilize the open circuit potential $\left(E_{\mathrm{ocp}}\right)$. Under steady $E_{\mathrm{ocp}}$, the potentiodynamic polarization test was executed within the potential from -250 to $250 \mathrm{mV}$ (vs. $E_{\text {ocp }}$ ) at $1 \mathrm{mV} / \mathrm{s}$ for copper in the naturally aerated ASW at $298 \mathrm{~K}$. EFM was conducted with a base frequency of $0.1 \mathrm{~Hz}$ using 2 and 5 as the multipliers; the measurements lasted for 16 cycles with a perturbation amplitude of $10 \mathrm{mV}$. According to the obtained electrochemical properties for uncoated and coated copper specimens, a passivated model was utilized to calculate the kinetic parameters from EFM spectra. EIS spectra for copper in ASW were obtained over a frequency range from $10^{5}$ to $10^{-2} \mathrm{~Hz}$ with a peak-to-peak amplitude of $10 \mathrm{mV}$. Every measurement was carried out in triplicate for reproducibility. All the electrochemical data were accessed by the Nova 2.1 software for the relevant parameters.

\subsection{Theoretical Study}

MD simulations were fulfilled via Materials Studio software (BIOVIA Inc., Vaucresson, France). By virtue of the velocity Verlet algorithm, the simulations were performed through integrating the motion equation [18]. The $\mathrm{Cu}(110)$ plane with the highest surface energy was chosen as the targeted surface, which was cleaved with five layers and frozen before the simulation. In particular, hydroxyl termination was used during the plane cleavage to build the hydroxylated copper surface. A vacuum layer of $20 \AA$ was placed over the $\mathrm{Cu}(110)$ plane to avoid virtual interactions. The supercell was enlarged to $33.19 \times 34.29 \times 44.61 \AA^{3}$, which accommodated 855 water molecules $\left(1 \mathrm{~g} / \mathrm{cm}^{3}\right), 10 \mathrm{Na}^{+}, 10 \mathrm{Cl}^{-}$and one PPy chain. Notably, the PPy chain with 15 repeat units was arranged randomly before the formal dynamic relaxation. This periodic box was subjected to geometric optimization under a COMPASS II forcefield; then, dynamic simulations were conducted under NVT ensemble (constant atom number, system volume and temperature), in which the temperature was kept at $298 \mathrm{~K}$ using a Nose thermoset with $1 \mathrm{fs}$ time step for $1000 \mathrm{ps}$. The last 100 frames of the equilibrium system were analyzed, from which the interaction energy $\left(E_{\text {int }}\right)$ for the PPy chain deposited on different copper surfaces was analyzed:

$$
E_{\text {int }}=E_{\text {tot }}-\left(E_{\text {surf }+ \text { sol }}+E_{\text {ppy }}\right)
$$

where $E_{\mathrm{tot}}, E_{\mathrm{surf}+\mathrm{sol}}$ and $E_{\mathrm{ppy}}$ are the energies of total system, the system without PPy and single PPy chains, respectively, $\mathrm{kJ} / \mathrm{mol}$. 


\section{Results and Discussion}

\subsection{Preparation and Characterization of PPy Coatings \\ 3.1.1. Preparation}

Figure 1a,b shows the representative voltammograms for in-situ electro-polymerizing PPy on passivated and hydroxylated copper surfaces, respectively. Generally, similar shapes are presented for the formation of p-PPy and d-PPy coatings, implicating the unaffected polymerization mechanism on divergent surfaces [19]. Besides, both oxidation waves in Figure $1 \mathrm{a}, \mathrm{b}$ are more prominent than the paired reduction moieties, which imply an oxidative polymerization nature (i.e., the formation of radical cations) for the pyrrole monomer [11,20]. In Figure 1a, the peak potential of monomer oxidation is gradually suppressed until the 7th scan, which directly evidences the deposition of PPy on the passivated surface due to the inferior conductivity of the polymer compared to the copper substrate [15]. Afterwards, the peak potential at roughly $0.73 \mathrm{~V}$ increases with the forward scans. It is well-acknowledged that a positive scan yields the electroactive PPy in the doped state, while the neutral eigenstate PPy accompanied by the de-doping of counter ions occurred during the backward (negative) scan [21]. The elevated oxidation potential is attributed to the accumulated electroactivity of the deposited PPy layer by periodic redox. Noticeably, negligible variation of oxidation potentials for 10th and 15th scans indicates that the deposition of PPy tends to be saturated at the copper/electrolyte interface [22].
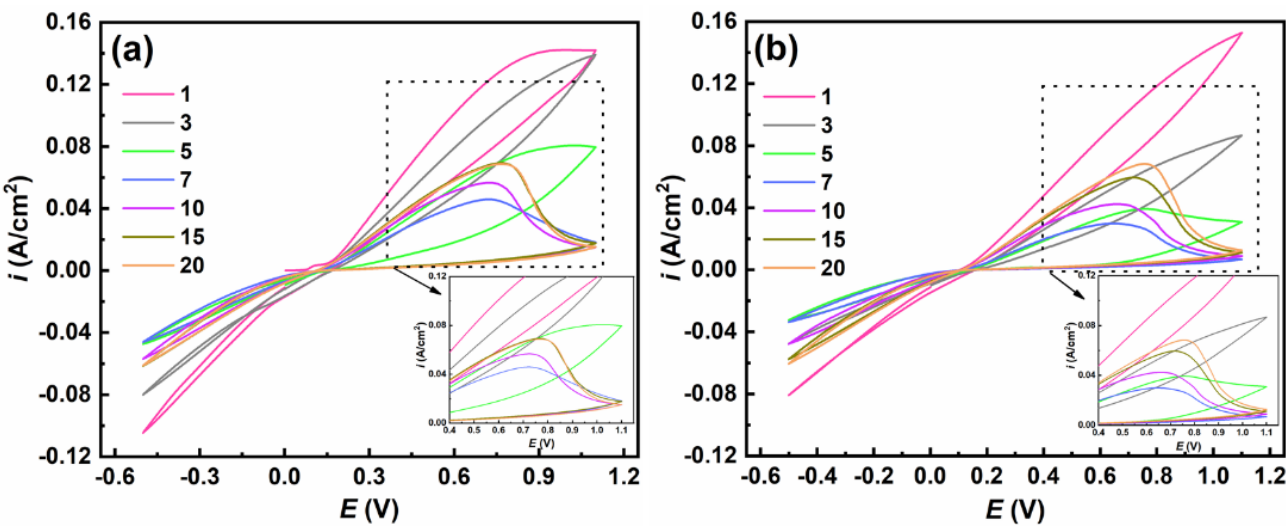

Figure 1. Voltammograms for the preparation of PPy through different surface pretreatments of copper surface: (a) conventional passivation (p-PPy), (b) plasma discharge (d-PPy); inset: close-up of the detailed anodic peaks.

For the formation of d-PPy shown in Figure 1b, a faster decline in oxidation potential over the p-PPy analogue signifies the rapid deposition of CPs on the hydroxylated copper surface [23]. Abundant hydroxyls can further increase the polarity of the copper surface, which is compatible with the excited radical cations during forward scan. As a result, oxidative PPy is prone to deposit on copper surfaces. Likewise, the stable growth of d-PPy coating starts from 7th scan, which exhibits persistent improvement of the electroactivity because of the continuously enlarged area of the oxidation wave (even over 15 cycles). Owing to the favorable affinity, more PPy chains can be stacked on the hydroxylated surface with higher electroactivity than those formed on the passivated counterpart. Closely packed CPs are bound to generate a compact coating architecture, which may achieve the pronounced anticorrosion capacity.

\subsubsection{Characterization}

Morphological observation visually distinguishes the coatings deposited on the different copper surfaces. SEM images of p-PPy and d-PPy coatings are shown in Figure $2 a, b$, respectively. In Figure 2a, a typical cauliflower-like structure is presented for $\mathrm{p}-\mathrm{PPy}$, which agrees well with other reports in the literature $[3,12,24]$. In contrast, a tightly packed morphology with small and inhomogeneous grains is shown in Figure $2 b$ for d-PPy coating. 
The compact coating structure is closely related to the favorable protection for the metal substrate against corrosive attack [25]. Similar ATR-FTIR spectra of p-PPy and d-PPy coatings given in Figure 2c consolidate the formation of CPs over different copper surfaces. In detail, the peak at $3420 \mathrm{~cm}^{-1}$ is assigned to the stretching of $-\mathrm{NH}$ along with the breathing behavior of its ring structure at $1655 \mathrm{~cm}^{-1}[26,27]$. C-N stretching is identified at $1413 \mathrm{~cm}^{-1}$; and the peak at $1098 \mathrm{~cm}^{-1}$ is credited to the vibration of C-H swelling [28]. Figure $2 \mathrm{~d}$ summarizes the physical properties of p-PPy and d-PPy, namely coating thickness, conductivity and adhesive grade. As expected, d-PPy $(13.37 \mu \mathrm{m})$ is thicker than p-PPy $(11.25 \mu \mathrm{m})$ for the preferential deposition of the polymer on the hydroxylated copper surface. The formed PPy chain may strongly bind with the -OH groups grafted on copper through charge transfer and/or hydrogen bonds. Tightly piled PPy chains inevitably reduce the voids that impair electron transmission across the different polymer backbone [29]. Consequently, the conductivity of d-PPy $(\sim 38.73 \mathrm{~S} / \mathrm{cm})$ is superior to that of p-PPy. Moreover, it is the firmly physicochemical interactions toward the hydroxylated copper surface that are responsible for the increased adhesion grade of d-PPy (5B).
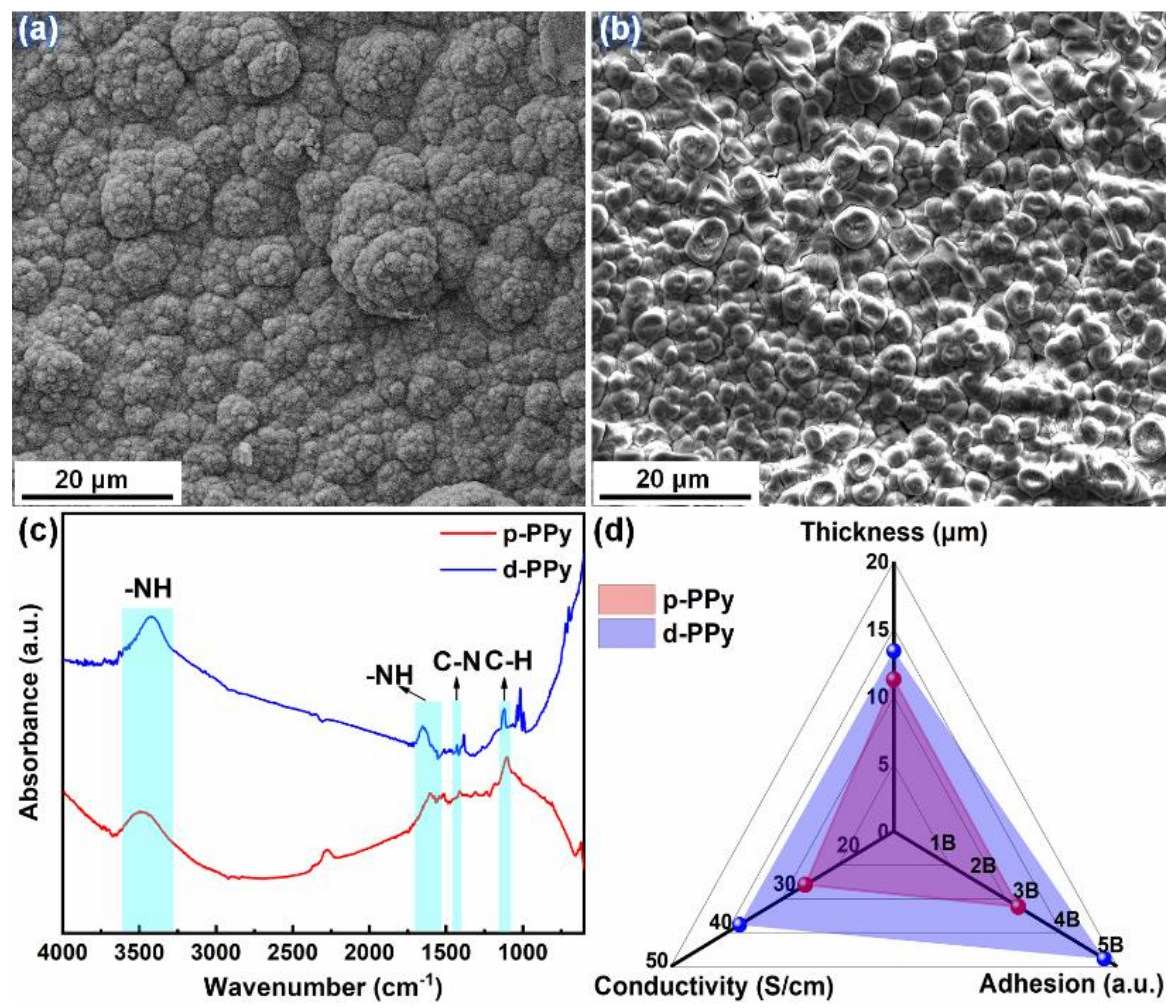

Figure 2. Surface morphologies of p-PPy (a) and d-PPy (b) along with the corresponding in-situ ATR-FTIR spectra (c) and physical characteristics (d) including coating thickness, conductivity and adhesive grade.

\subsection{Anticorrosive Evaluations of Different PPy Coatings}

\subsubsection{Electrochemical Thermodynamics and Kinetics}

Foremost, the corrosion resistance of p-PPy and d-PPy coatings for copper in ASW was evaluated by $E_{\text {ocp }}$ monitoring and potentiodynamic polarization as shown in Figure 3. Figure 3a displays the evolution of $E_{\text {ocp }}$ during the long-term immersion in ASW at $298 \mathrm{~K}$. Clearly, $E_{\text {ocp }}$ values for passivated copper, p-PPy- and d-PPy-coated specimens reach pseudo-equilibrium after $240 \mathrm{~h}$ immersion, the magnitudes of which follow the order of $\mathrm{d}-\mathrm{PPy}>\mathrm{p}$-PPy $>$ passivated copper. Hence, the coated specimen is more corrosion-resistant than passivated copper in ASW from the thermodynamic point of view [30]. In addition, the noblest $E_{\mathrm{ocp}}$ value for d-PPy-coated copper demonstrates its superior anticorrosion performance for the copper underneath. The polarization curves for $\mathrm{p}$-PPy-coated specimen 
after the pre-set immersion intervals in ASW are shown in Figure 3b. As is seen, both anodic and cathodic reactions are aggravated as the immersion period augments the curve shifting toward the high current density area. This also indicates that the protective capacity of p-PPy is gradually deteriorated for copper in ASW. In particular, in the initial $24 \mathrm{~h}$ immersion, $\mathrm{p}$-PPy-coated copper exhibits eminent anodic passivation at an overpotential greater than $\sim 0.58 \mathrm{~V}$. This reveals the anodic protection effect of PPy, which passivates the underlying metals [7]. However, with the extension of the immersion time, few signs of passivation are detected on the anodic branches as illustrated in Figure 3b. Therefore, p-PPy may lose its anodic protection ability after long-term immersion in ASW. For the d-PPy-coated specimen shown in Figure 3c, the curve still moves toward the high current density region; however, the surface passivation is maintained as the immersion period continues over $168 \mathrm{~h}$. The persistent passivation behavior articulates the strong anodic protection effect of d-PPy coating for copper surfaces in ASW.
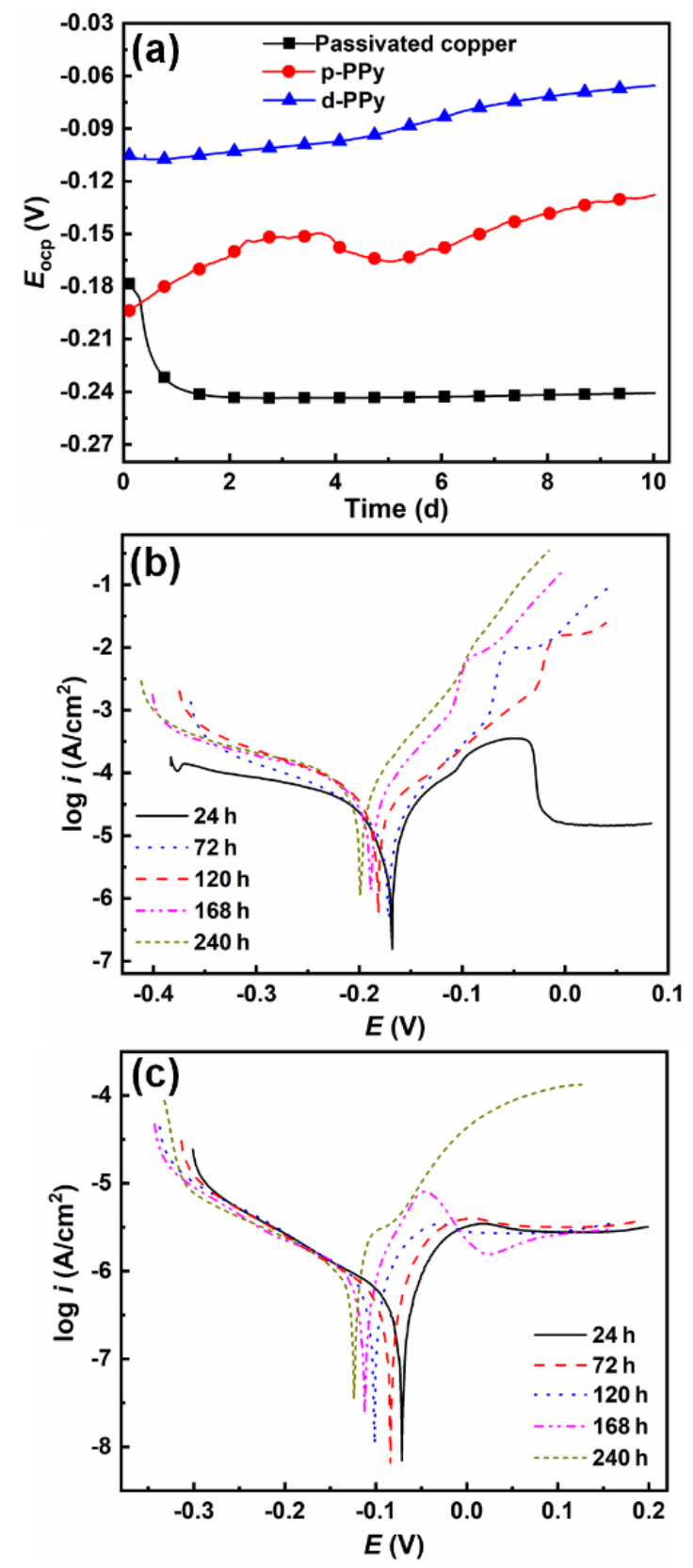

Figure 3. Evolution of $E_{\mathrm{ocp}}$ with time (a) for passivated, p-PPy- and d-PPy-coated copper specimens and the polarization curves for $\mathrm{p}-\mathrm{PPy}(\mathbf{b})$ and d-PPy (c) after allocated immersion intervals. 
To quantitatively assess the protective capability of PPy coatings for copper in ASW, kinetic parameters, including the corrosion potential $\left(E_{\text {corr }}\right)$, corrosion current density $\left(i_{\text {corr }}\right)$, anodic $\left(\beta_{\mathrm{a}}\right)$ and cathodic $\left(\beta_{\mathrm{c}}\right)$ slopes, were derived through the Butler-Volmer equation [15], and the relevant parameters are tabulated in Table 2. It is noteworthy that the linear portion is hardly defined in the polarization curves with the passivation feature. Thus, the corresponding $\beta_{\mathrm{a}}$ is absent in Table 2. For both p-PPy- and d-PPy-coated specimens, $E_{\text {corr }}$ becomes less noble as the immersion time increases, implying that the corrosion tendency is deteriorated for copper in ASW [31]. In the case of the sample protected by p-PPy, $i_{\text {corr }}$ sharply increases from 25.41 to $63.79 \mu \mathrm{A} / \mathrm{cm}^{2}$ as the immersion period increases from 24 to $240 \mathrm{~h}$, respectively. This explicitly reveals the intensified corrosion reaction at the copper/solution interface. The declining trend of the presented $\beta_{\mathrm{a}}$ and $\beta_{\mathrm{c}}$ also indicates the attenuated corrosion resistance of the p-PPy-coated specimen. In contrast, the $i_{\text {corr }}$ value for the d-PPy-coated specimen is one order of magnitude lower than that for its p-PPy-protected counterpart at each exposure period. The reduced $i_{\text {corr }}$ value is a feature of the significantly delayed metal dissolution in ASW for copper protected by d-PPy. By virtue of the admirable anodic protection and physical barrier, $i_{\text {corr }}$ merely increases to $3.09 \mu \mathrm{A} / \mathrm{cm}^{2}$ for the coated sample after $240 \mathrm{~h}$ of immersion in the corrosive medium. Compared with the specimen protected by $\mathrm{p}$-PPy, the superior anticorrosion performance of d-PPy may be attributed to the intact and compact coating architecture besides the intrinsic electroactivity.

Table 2. Electrochemical kinetic parameters for p-PPy and d-PPy coated copper after allocated immersion intervals.

\begin{tabular}{cccccc}
\hline Sample & Time $(\mathbf{h})$ & $\boldsymbol{E}_{\text {corr }}(\mathbf{m V})$ & $\boldsymbol{i}_{\text {corr }}\left(\boldsymbol{\mu A} / \mathbf{c m}^{2}\right)$ & $\beta_{\mathbf{a}}(\mathbf{m V} / \mathbf{d e c})$ & $-\beta_{\mathbf{c}}(\mathbf{m V} / \mathbf{d e c})$ \\
\hline p-PPy & 24 & -168 & 25.41 & $/$ & 128.19 \\
& 72 & -171 & 26.25 & 114.26 & 109.61 \\
& 120 & -181 & 33.08 & 111.49 & 110.23 \\
& 168 & -189 & 60.13 & 95.60 & 104.58 \\
$\mathrm{~d}-\mathrm{PPy}$ & 240 & -199 & 63.79 & 98.73 & 99.89 \\
& 24 & -71 & 0.68 & $/$ & 93.94 \\
& 72 & -84 & 1.07 & $/$ & 98.29 \\
& 120 & -101 & 1.93 & $/$ & 101.76 \\
& 168 & -112 & 2.25 & 95.87 & 99.04 \\
\hline
\end{tabular}

Considering that $i_{\text {corr }}$ obtained from the polarization technique may include the redox current of the electroactive polymer, non-destructive electrochemical kinetic examination (i.e., EFM) is recommended to further verify the protective nature of PPy coatings [32]. EFM spectra for specimens protected by p-PPy and d-PPy along with the derived kinetic parameters, including the apparent current density $\left(i_{\text {corr-F }}\right)$, causality factors 2 (CF2) and 3 (CF3), are summarized in Figure 4. Figure 4a,b display the EFM spectra of copper coated with p-PPy and d-PPy, respectively. As is observed, the current densities at excited $(0.2$ and $0.5 \mathrm{~Hz}$ ), harmonic (e.g., 0.4 and $1.0 \mathrm{~Hz}$ ) and intermodulation (e.g., 0.3 and $0.7 \mathrm{~Hz}$ ) frequencies are much more prominent than the background noise, validating the effectiveness of measurements [33]. Furthermore, the EFM spectrum is elevated with the extension of the immersion time for both coated systems as shown in Figure $4 a$, b, which indicates the intensified $i_{\text {corr-F }}$ at copper/electrolyte interface. The derived kinetic parameters of $\mathrm{p}$-PPyand d-PPy-coated specimens are presented in Figure 4c,d, respectively. Obviously, CF2 and CF3 indices close to the respective ideal values (i.e., 2 and 3) imply excellent linearity and causality of the EFM determinations [34]. Moreover, $i_{\text {corr-F }}$ monotonously increases with time for both coated systems. Thus, prolonging the exposure duration is detrimental to the protective performance of both conductive coatings for copper in ASW. Similarly to the polarization tests, the $i_{\text {corr-F }}$ for the d-PPy-protected specimen is one order of magnitude lower than that for the specimen coated with p-PPy, signifying the preferable anticorrosion capacity of d-PPy coating. 

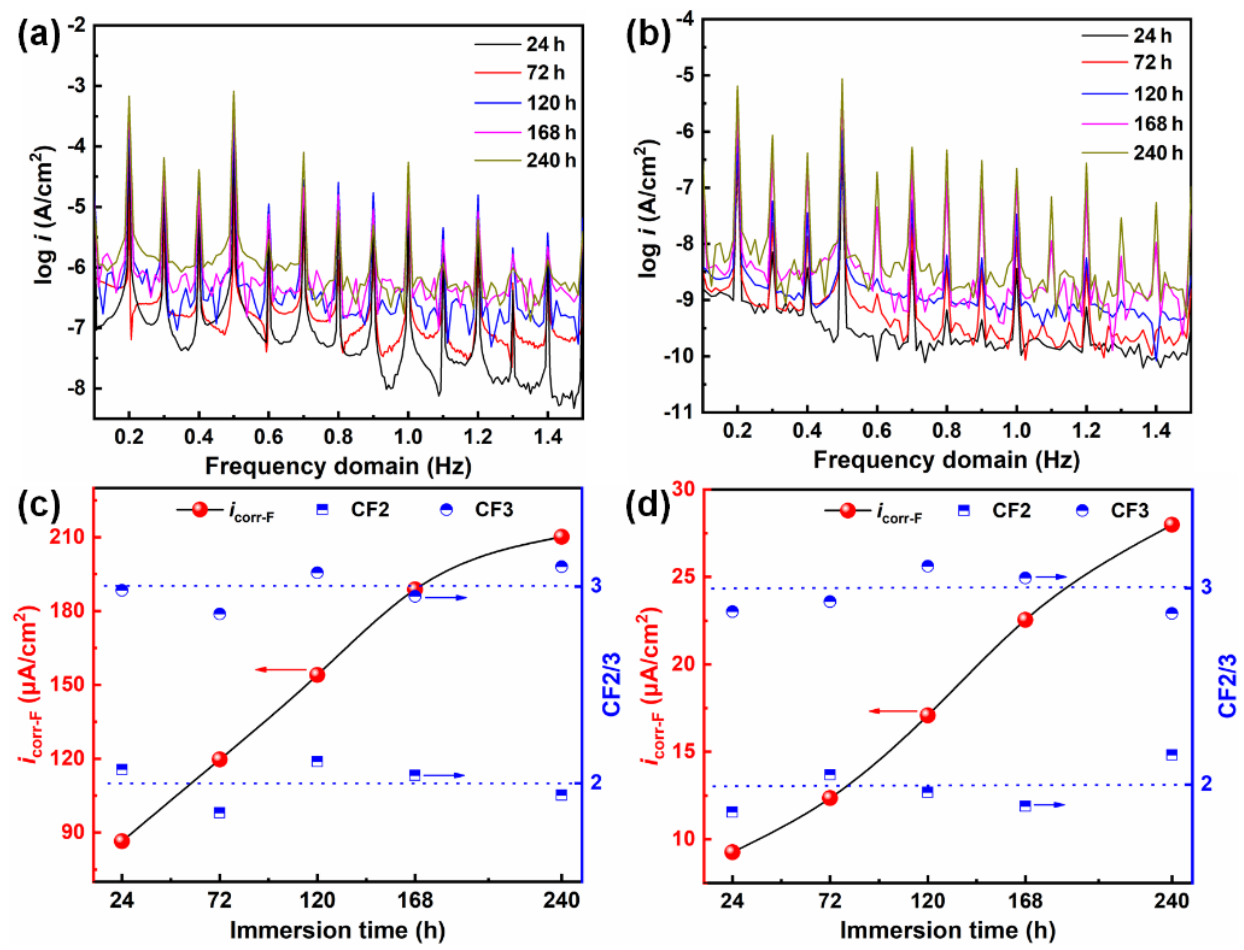

Figure 4. EFM spectra for copper specimens coated by p-PPy (a) and d-PPy (b) after allocated immersion intervals along with the derived kinetic parameters $(\mathbf{c}, \mathbf{d})$ including apparent corrosion current density $\left(i_{\text {corr-F}}\right)$, causality factors 2 and 3.

Additional insight on Figure $4 \mathrm{c}, \mathrm{d}$ indicates that $i_{\text {corr-F }}$ is one or two orders of magnitude larger than that acquired from potentiodynamic polarization. Regardless of the errors caused by different techniques, the apparent increment in $i_{\text {corr-F }}$ should be ascribed to the redox activity of $\mathrm{CP}$ coating immersed in the aggressive electrolyte [35]. In detail, an electroactive polymer, especially in the doped state, would exchange charge and subsequently be neutralized with the surrounding ions. Hence, the apparent $i_{\text {corr-F }}$ should be simultaneously comprised with the component of corrosion reaction at the copper/solution interface and the redox portion of conductive PPy. Accordingly, $i_{\text {corr-F }}$ values determined by EFM are larger than those derived from polarization tests. Following the neutralization of doped polymer, the conductive coating deservedly loses anodic protection performance for the substrate; even worse, reduction and ultimate degradation could occur for PPy coating during long-term immersion in ASW. As a result, $i_{\text {corr-F }}$ increases with the augment in the exposure period. It is also worthy of note in Figure $4 \mathrm{c}, \mathrm{d}$, that the variation trend of $i_{\text {corr-F }}$ is the same as that related to $i_{\text {corr }}$ as compiled in Table 2 . This suggests that the dominant anticorrosion mechanism may result from the physical barrier effect of electro-polymerized coatings due to the feeble influence of electroactivity on the corrosion current variation [36].

\subsubsection{EIS}

EIS was also conducted to ascertain the protective mechanism of as-prepared coatings for copper in ASW. Figure 5a,b shows the Nyquist spectra for specimens coated with the respective p-PPy and d-PPy after different immersion times in ASW at $298 \mathrm{~K}$. In Figure 5a, the plots for p-PPy-coated copper consist of a capacitance arc at high- and medium-frequency regions, and Warburg diffusion $(W)$ at the low-frequency region. Thus, two time constants emerge for the impedance responses [37], which reveal the penetration and diffusion of corrosive species inward coating defects. In addition, the curvature radius of the capacitance arc in Figure 5a progressively shrinks with the extension of time, indicating the reduced resistance for charge transfer across the copper/electrolyte interface [30]. Besides, the diffusion of corrosive species becomes increasingly obvious 
due to the clear $W$ element at low frequencies. For Nyquist plots displayed in Figure $5 b$, a negligible diffusion phenomenon is observed for d-PPy-protected specimens even after $120 \mathrm{~h}$ of immersion, although the diameter of the high-frequency arc is responsible for the reducing trend. The lack of low-frequency $W$ element indicates the highly restrained diffusion of aggressive species at the copper/coating interface [12]. The intact d-PPy architecture prevents the corrosive media from diffusing and the subsequent penetration toward the copper surface. Retarding the diffusion of corrosive species is one of the most efficient ways to reinforce the protection efficacy of coatings.
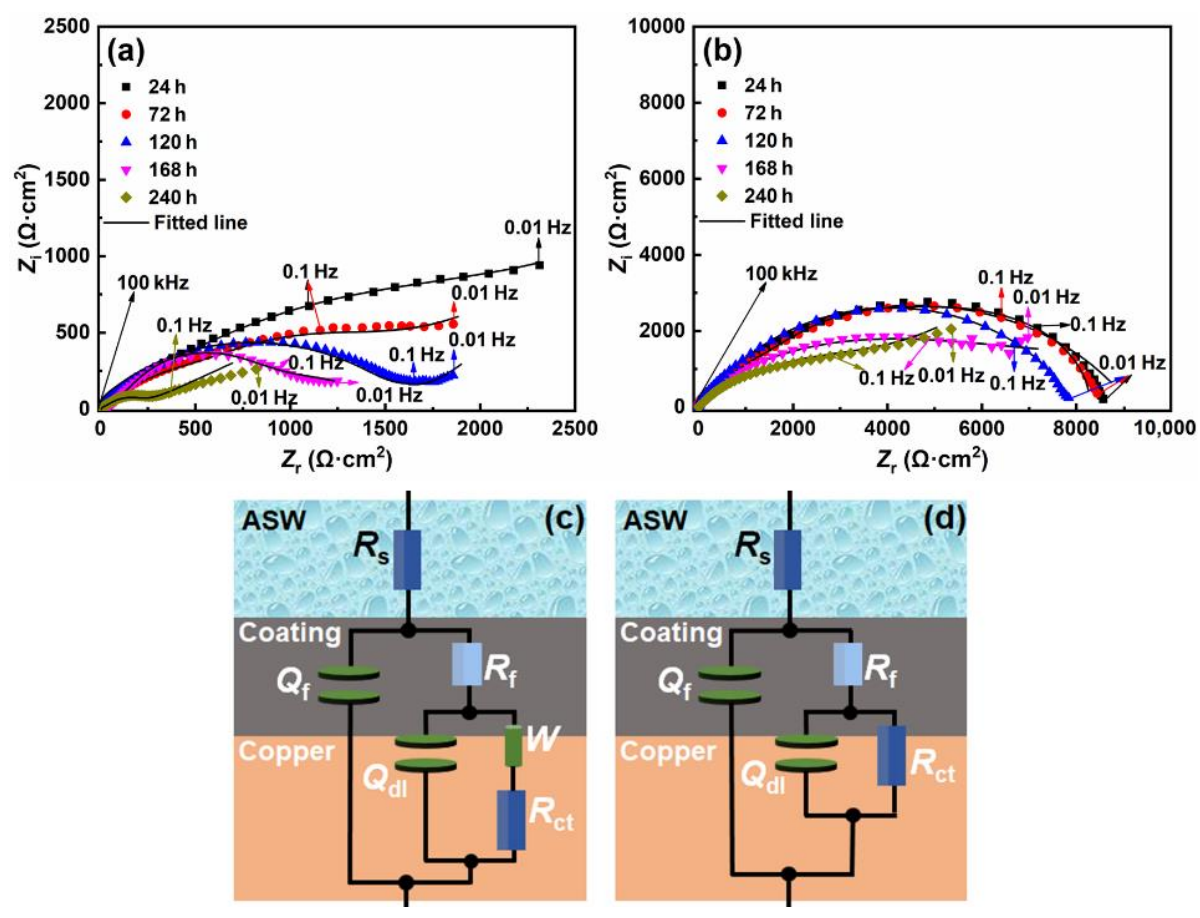

Figure 5. EIS spectra of p-PPy (a) and d-PPy (b)-coated copper after allocated immersion intervals in ASW at $298 \mathrm{~K}$ along with the equivalent circuits (c,d).

The equivalent circuits depicted in Figure $5 c, d$ were suitable for quantifying impedance parameters including solution resistance $\left(R_{\mathrm{S}}\right)$, film resistance $\left(R_{\mathrm{f}}\right)$ and charge transfer resistance $\left(R_{\mathrm{ct}}\right)$. Particularly, the constant phase angle element $(Q)$ was utilized in the fitting procedure to compensate for the dispersion effect, whose impedance $\left(Z_{Q}\right)$ can be expressed by the following equation [38]:

$$
Z_{\mathrm{Q}}=\frac{1}{Y_{0}(j \omega)^{n}}
$$

where $Y_{0}$ is proportional factor; $j$ is the imagery root; $\omega$ is the angle frequency $(2 \pi f)$; and $n$ is the index of phase shift. To better understand the tolerance of coatings, the related capacitances, namely film capacitance $\left(C_{\mathrm{f}}\right)$ and double layer capacitance $\left(C_{\mathrm{dl}}\right)$, were calculated as per the following expressions [19]:

$$
\begin{gathered}
C_{\mathrm{f}}=Y_{0}\left(\omega^{\prime}\right)^{n-1} \\
C_{\mathrm{dl}}=\left[Y_{\mathrm{dl}}\left(\frac{1}{R_{\mathrm{s}}}+\frac{1}{R_{\mathrm{ct}}}\right)^{n-1}\right]^{-n}
\end{gathered}
$$

where $\omega^{\prime}$ is the angle frequency at the maximum imaginary value; and $Y_{\mathrm{dl}}$ is the proportional factor for $Q_{\mathrm{dl}}$. The impedance parameters are listed in Table 3. $R_{\mathrm{f}}$ denotes the barrier function of the coated layer that isolates the substrate from aggressive attack [17]. The magnitude of $R_{\mathrm{f}}$ for both coatings is incomparable with the reported eigenvalues of inert 
polymer counterparts (e.g., epoxy resin) due to their moderate conductivity [3]. Even so, the $R_{\mathrm{f}}$ of d-PPy-coated sample is higher than that of the p-PPy-protected counterpart after each immersion period, which arises from the compact coating structure of d-PPy. However, $R_{\mathrm{f}}$ monotonously decreases with time for both coatings, a sign of the depressed barrier effect [22]. This reveals that ASW is penetrating inward the coating, and subsequently causes the second time constant (i.e., diffusion behavior). Thereby, an increasing $W$ value is observed for copper protected by p-PPy. Regarding the superior conductivity of d-PPy, its anodic protection effect is intensified for the substrate compared to that of p-PPy yielding a higher $R_{\mathrm{f}}$. The uptake electrolyte for both coatings can be also verified by the increasing $C_{\mathrm{f}}$ value as the time advances [14]. Due to the continuous corrosive attack, $n_{\mathrm{f}}$ values of both coatings are seriously deviated from the ideal unity.

Table 3. Impedance parameters for p-PPy (a) and d-PPy (b) coated copper after allocated immersion intervals in ASW at $298 \mathrm{~K}$.

\begin{tabular}{|c|c|c|c|c|c|c|c|c|c|}
\hline Sample & $\begin{array}{l}\text { Time } \\
\text { (h) }\end{array}$ & $\begin{array}{c}R_{\mathrm{s}} \\
\left(\Omega \cdot \mathrm{cm}^{2}\right)\end{array}$ & $\begin{array}{c}R_{\mathrm{f}} \\
\left(\mathrm{k} \Omega \cdot \mathrm{cm}^{2}\right)\end{array}$ & $\begin{array}{c}C_{f} \\
\left(\mu F / \mathrm{cm}^{2}\right)\end{array}$ & $n_{\mathrm{f}}$ & $\begin{array}{c}R_{\mathrm{ct}} \\
\left(\mathrm{k} \Omega \cdot \mathrm{cm}^{2}\right)\end{array}$ & $\begin{array}{c}C_{\mathrm{dl}} \\
\left(\mu \mathrm{F} / \mathrm{cm}^{2}\right)\end{array}$ & $n_{\mathrm{dl}}$ & $\begin{array}{c}W \\
\left(\mathrm{~m} \Omega \cdot \mathrm{cm}^{2} \cdot \mathrm{s}^{1 / 2}\right)\end{array}$ \\
\hline \multirow[t]{5}{*}{ p-PРy } & 24 & 2.36 & 206.70 & 99.14 & 0.58 & 1.96 & 85.57 & 0.75 & 4.04 \\
\hline & 72 & 3.31 & 137.84 & 113.20 & 0.55 & 1.85 & 88.29 & 0.73 & 9.75 \\
\hline & 120 & 2.19 & 135.25 & 120.35 & 0.57 & 1.59 & 93.56 & 0.69 & 2.33 \\
\hline & 168 & 4.02 & 98.68 & 122.84 & 0.53 & 0.96 & 109.79 & 0.68 & 3.97 \\
\hline & 240 & 3.37 & 96.23 & 131.71 & 0.58 & 0.45 & 123.25 & 0.66 & 11.20 \\
\hline \multirow[t]{5}{*}{ d-PPy } & 24 & 1.08 & 435.29 & 68.29 & 0.61 & 8.36 & 57.44 & 0.78 & / \\
\hline & 72 & 3.94 & 434.57 & 68.31 & 0.59 & 8.28 & 57.59 & 0.77 & / \\
\hline & 120 & 5.21 & 406.79 & 75.59 & 0.55 & 7.33 & 61.06 & 0.78 & / \\
\hline & 168 & 2.73 & 358.44 & 80.14 & 0.58 & 5.84 & 68.25 & 0.74 & 5.25 \\
\hline & 240 & 5.58 & 321.02 & 83.22 & 0.60 & 4.38 & 71.97 & & 7.03 \\
\hline
\end{tabular}

The $R_{\mathrm{ct}}$ of the d-PPy-coated specimen is always larger than that of its p-PPy-protected counterpart during the prolonged exposure period, indicating a lower degree of electron transfer across the copper/d-PPy coating interface. Due to the inferior coating compactness, the $R_{\mathrm{ct}}$ of the p-PPy-coated specimen decreases from $1.96 \mathrm{k} \Omega \cdot \mathrm{cm}^{2}$ after $24 \mathrm{~h}$ of immersion to $0.45 \mathrm{k} \Omega \cdot \mathrm{cm}^{2}$ at the end of exposure. On the contrary, by virtue of its fair conductivity and strong adhesion grade, the d-PPy-coated specimen earns a relatively high interfacial resistance toward charge transfer at an early stage (within $72 \mathrm{~h}$ ). It is because of the high $R_{\mathrm{ct}}$ that the diffusion phenomenon of corrosive species and/or corroded products is highly restrained until the completion of $168 \mathrm{~h}$ immersion. Likewise, prolonging the immersion time is detrimental to the protective performance of d-PPy for the reduced $R_{\mathrm{ct}}$ value to $4.38 \mathrm{k} \Omega \cdot \mathrm{cm}^{2}$ after $240 \mathrm{~h}$ of exposure in ASW. By contrast, subsequent to the long-term immersion in ASW, $R_{\text {ct }}$ related to the sample coated with d-PPy is still one order of magnitude higher than that associated with the p-PPy-protected sample. The robust protection effect of d-PPy for copper benefits from its satisfactory compactness. The increase in $C_{\mathrm{dl}}$ with time for both coatings also results from the infiltration of electrolyte into the Helmholtz plane along the copper/coating interface [37]. Efficient protection of the d-PPy coating generates a smoother and more homogeneous copper surface (i.e., higher $\left.n_{\mathrm{dl}}\right)$ than that for the specimen coated with p-PPy.

On the whole, electrochemical analyses of the coated specimens demonstrate that d-PPy exerts superior anodic protection and barrier effect for copper over the p-PPy analog due to the distinct electroactivity and intact coating architecture.

\subsection{Surface and Interface Characterizations}

Interfacial wettability was employed to check the tolerance of both coated specimens. The static water contact angles for specimens protected by p-PPy and d-PPy coatings before and after $240 \mathrm{~h}$ of immersion in ASW at $298 \mathrm{~K}$ are illustrated in Figure 6a,b, respectively. Obviously, the p-PPy-coated copper surface has an average contact angle of $78.9^{\circ}$ as shown in Figure 6a. Unlike the hydrophobic features of most organic coatings, the hydrophilic 
surface may stem from the capillary effect caused by micro-pores and/or defects in the p-PPy layer [39]. Even worse, the contact angle sharply decreases to $50.4^{\circ}$ for this specimen after $240 \mathrm{~h}$ of immersion in ASW, which can be attributed to the serious deterioration of the p-PPy coating. In addition, little coating is found in Figure $6 \mathrm{c}$ due to the total reduction and the ensuing degradation of PPy by the corrosive attack of ASW. Instead, a thin composite passivation layer is seen as confirmed by EDS spectrum (Figure 6e), which may stem from the compelling of electroactive PPy with strong interfacial electron-mediation ability [15]. The passivated $\mathrm{Cu}(\mathrm{I})$ and / or $\mathrm{Cu}(\mathrm{II})$ oxides could exert certain protective effects over the substrate [4]. On the contrary, a hydrophobic appearance (contact angle of $91.3^{\circ}$ ) is found in Figure $6 \mathrm{~b}$ for fresh d-PPy coating. A high contact angle endows the coatings with low surface energy. Besides, intact coating architecture ensures better water repulsion after immersion in ASW, which facilitates the anticorrosion efficacy for copper in the aggressive medium [6]. After long-term immersion in ASW, the contact angle also lowers to $65.1^{\circ}$ for the partial degradation of the PPy chain, and thus the failure in protection performance. In contrast, the cauliflower-like PPy feature can be still distinguished in Figure $6 \mathrm{~d}$ after $240 \mathrm{~h}$ of immersion in ASW, which convincingly illustrates the robust coating and the favorable corrosion retardation performance of $\mathrm{d}-\mathrm{PPy}$ for the underlying copper. The considerable content of $\mathrm{C}, \mathrm{N}$ and $\mathrm{O}$ elements in Figure $6 \mathrm{f}$ further consolidate the anchored d-PPy coating over the substrate. This also discloses that the hydroxylated copper surface prompts the generation of well-adhered PPy coating. Another aspect, the presence of S, $\mathrm{Cl}$ and $\mathrm{K}$ elements in the figure, should be assigned to the dissolved salts in ASW. During long-term immersion, in-situ ions (Table 1) inevitably penetrate into the coating matrix, and are hardly washed out before the measurement.

(a)

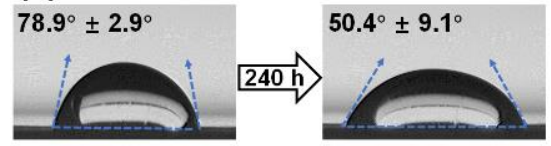

(c)
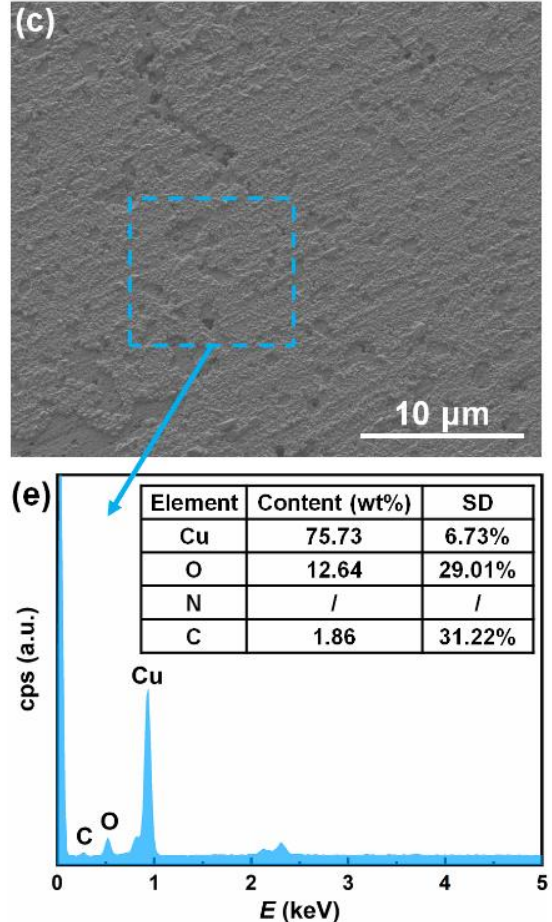

(b)
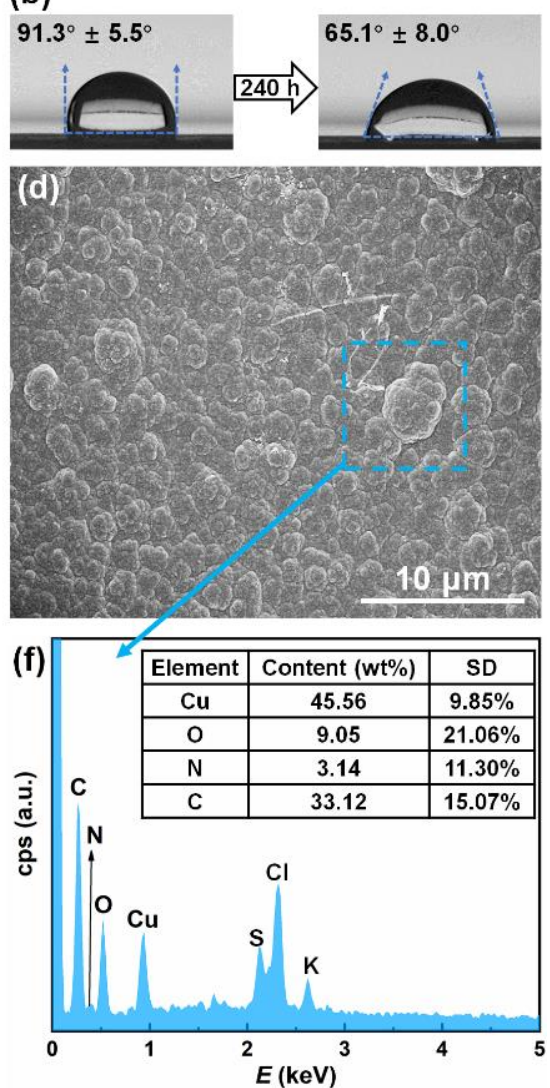

Figure 6. Evolution of static water contact angle for p-PPy (a) and d-PPy (b) coated copper specimens before and after $240 \mathrm{~h}$ immersion in ASW at $298 \mathrm{~K}$, and the final surface morphologies ((c) p-PPy; (d) d-PPy) with the corresponding EDS spectra of framed areas ((e) for the area in (c); (f) for the area in $(\mathbf{d})$ ). 


\subsection{Molecular Dynamics Simulation}

Exploring the actual deposition mechanism has noteworthy meaning for the clarification of strong interactions between the conductive polymer and the modified copper surface. Therefore, MD simulations were conducted for the PPy chain depositing on the copper surface in the saline media at $298 \mathrm{~K}$. Figure 7 displays the outcomes for deposition courses of the PPy chain on pristine and hydroxylated $\mathrm{Cu}(110)$ planes. As can be seen in Figure 7a, the single-stranded PPy exhibits a turnup configuration on the $\mathrm{Cu}(110)$ plane with partial segments orientating toward the bulk solution. Conceivably, the deposited layer fabricated from the stacking of distorted chains could cause inter-chain voids, and thereby yield the loose and porous coating architecture. Such coating defects can serve as transmission paths for corrosive species across the barrier. In contrast, Figure $7 \mathrm{~b}$ presents the intimate contact between the PPy chain and the hydroxylated copper plane through a totally parallel configuration. This deposition manner favors the tight packing of PPy chains on the metal surface, and accounts for the favorable protection efficacy of copper in ASW [38]. Furthermore, interaction energy $\left(E_{\text {int }}\right)$ is frequently utilized to judge the binding tendency for adsorbates on the substrate [18]. $E_{\text {int }}$ values were calculated as -1358.62 and $-2274.09 \mathrm{~kJ} / \mathrm{mol}$ for the deposition of PPy on pristine and hydroxylated $\mathrm{Cu}(110)$ planes, respectively. The negative sign of $E_{\text {int }}$ indicates the spontaneity of the deposition of PPy on both surfaces; meanwhile, the large magnitude of the $E_{\text {int }}$ value also suggests firm binding between the PPy and the copper surface [25]. Remarkably, the $E_{\text {int }}$ for PPy depositing on the hydroxylated copper surface is apparently higher than that for the deposition process on the pristine plane, which implies the preferential formation of the PPy layer on the modified surface with strong binding energy.
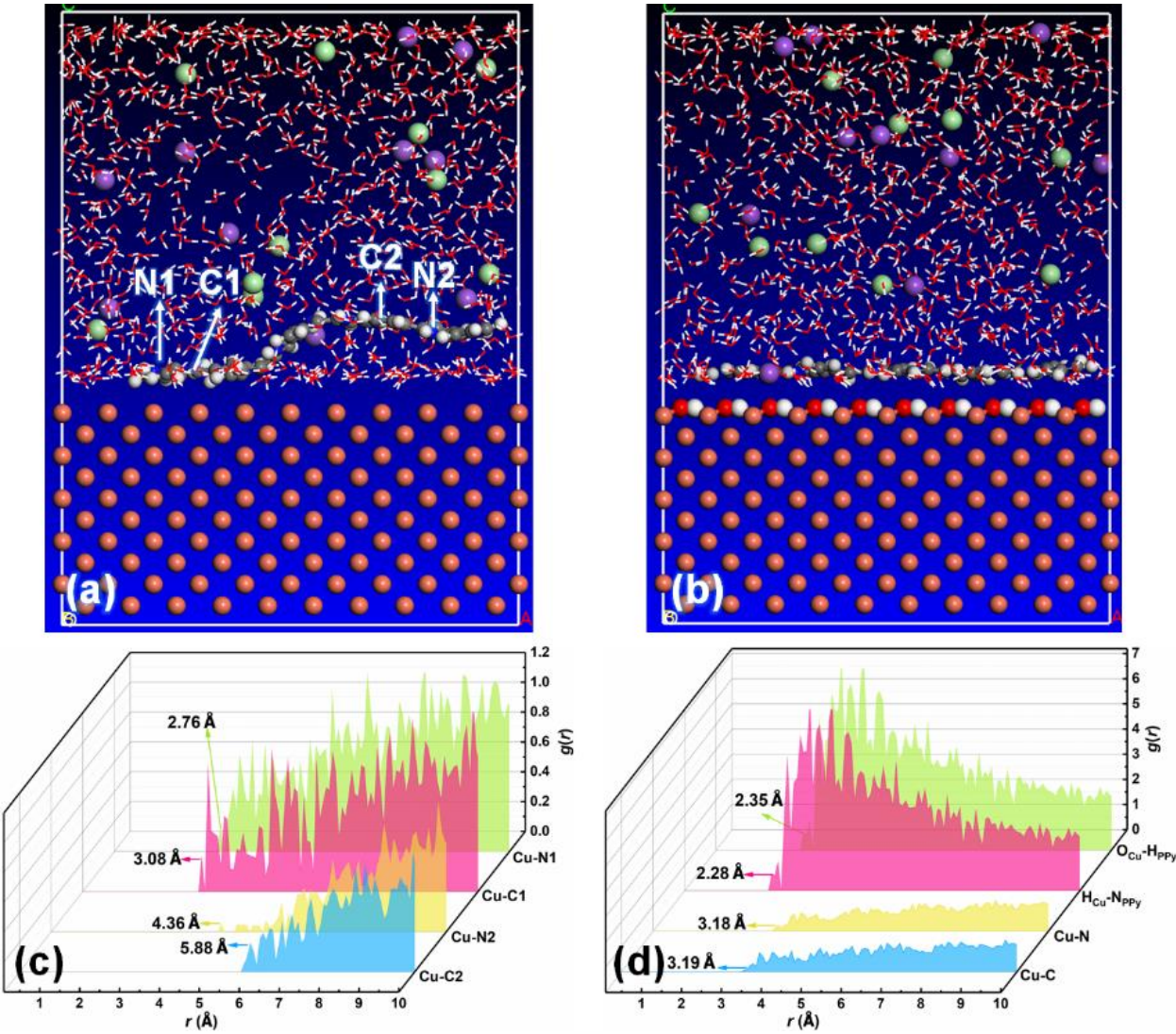

Figure 7. Equilibrium deposition configurations of p-Ppy (a) and d-Ppy (b) on Cu (110) plane at $298 \mathrm{~K}$, along with the corresponding RDF analyses between surface atoms on copper and the selected atoms on PPy chain ((c) for p-PPy; (d) for d-PPy). 
Radial distribution function (RDF, $g(r)$ ) was deployed from MD simulation outcomes to reveal in-depth the nature of the interaction between PPy and the copper surface, which can be expressed as follows [15]:

$$
g(r)=\frac{1}{\rho_{\mathrm{B}-\mathrm{loc}}} \times \frac{1}{N_{\mathrm{A}}} \sum_{i \in \mathrm{A}}^{N_{\mathrm{A}}} \sum_{j \in \mathrm{B}}^{N_{\mathrm{B}}} \frac{\delta\left(r_{\mathrm{ij}}-r_{\mathrm{d}}\right)}{4 \pi r_{\mathrm{d}}^{2}}
$$

where $\rho_{\mathrm{B}-\mathrm{loc}}$ is the probability density of particle B over all shells around particle $\mathrm{A}$; and $r$ is the search radius for $B$. The relevant analyses are depicted in Figure $7 c, d$. Regarding the distorted configuration of PPy on the pristine $\mathrm{Cu}(110)$ plane, typical condensed atoms (i.e., $\mathrm{C}$ and $\mathrm{N}$ ) on the polymer are subdivided into two categories: $\mathrm{C} 1$ and $\mathrm{N} 1$ are located on the tightly contact moiety of PPy, while C2 and N2 lie on the other portion, apart from the copper plane. As for the hydroxylated $\mathrm{Cu}(110)$ plane, the interaction between the $\mathrm{H}$ atom on the PPy and $\mathrm{O}$ atom grafted onto the copper surface $\left(\mathrm{O}_{\mathrm{Cu}}-\mathrm{H}_{\mathrm{PPy}}\right)$, and that between the $\mathrm{N}$ atom on the PPy and the $\mathrm{H}$ atom from the copper surface $\left(\mathrm{N}_{\mathrm{PPy}}-\mathrm{H}_{\mathrm{Cu}}\right)$ are considered to scrutinize the potential binding mechanism. Besides, the interactions between condensed atoms (i.e., $\mathrm{C}$ and $\mathrm{N}$ ) and the copper atom are also checked for obligation. Generally, the $r$ value of the initial peak in the RDF curve signifies the nature of the interaction between the targeted atoms. In detail, a chemical bonding occurs when $r$ is less than $3.2 \AA$; an $r$ value between 3.2 and $5.0 \AA$ incurs strong physical interaction; and an $r$ value over $5.0 \AA$ means a weak van der Waals force [28]. In Figure 7c, the binding tendencies of $C 1$ and $\mathrm{N} 1$ towards the copper surface are more obvious than those of C2 and N2 for the more significant peak intensities of the RDF curve. This is credited to the strong affinity of $C 1$ and N1 to the copper surface. Moreover, $r$ values of the initial RDF peak for $\mathrm{Cu}-\mathrm{C} 1$ and $\mathrm{Cu}-\mathrm{N} 1$ were found to be 3.08 and $2.76 \AA$, respectively, which denote the chemical bonding for $\mathrm{C} 1$ and N1 on PPy toward the copper surface. For RDF curves described in Figure 7d, the binding strengths of typical atoms on the PPy chain toward the hydroxylated layer on the copper surface are more predominant than those toward inner copper atoms. Thus, strong interaction between PPy and the hydroxylated layer can be deemed as the driving force for the polymer deposition, which accords well with the preceding inference on the binding mechanism of PPy on copper surface. The values of $r$ associated with $\mathrm{O}_{\mathrm{Cu}}-\mathrm{H}_{\mathrm{PPy}}$ and $\mathrm{N}_{\mathrm{PPy}}-\mathrm{H}_{\mathrm{Cu}}$ are identified at 2.28 and $2.35 \AA$, respectively, implying the donor-acceptor interacting nature between $\mathrm{C}$ and $\mathrm{N}$ atoms on PPy and the hydroxylated layer of the copper surface. Meanwhile, the $r$ values of $\mathrm{Cu}-\mathrm{C}$ and $\mathrm{Cu}-\mathrm{N}$ are also located in the chemical bonding region (3.19 and $3.18 \AA$, respectively), which reveals that the PPy chain can also intensively interact with the internal copper atoms.

\section{Conclusions}

Plasma discharging pretreatment was deployed on the copper surface for the firm deposition of PPy and subsequent protection efficacy against corrosive attack by ASW. Surface morphology, ATR-FTIR spectra and physical properties collectively evidence the strong adhesion and superior conductivity of the d-PPy coating on the copper surface. Electrochemical thermodynamics and kinetics revealed the favorable anticorrosion performance of d-PPy coating for copper in ASW. The mechanism of tight deposition and high-performance protection for PPy on hydroxylated copper surfaces was clarified by MD simulations. The remarkable conclusions involved the following points.

1. The hydrophilic copper surface could be established after the surface treatment of plasma discharging (hydroxylation); and the electro-polymerized PPy deposited on the hydroxylated surface (i.e., d-PPy) faster than that formed over the passivated counterpart. Due to the preferential deposition, d-PPy possessed tight coating architecture with a thickness of $13.37 \mu \mathrm{m}$, an adhesive grade of $5 \mathrm{~B}$ and a conductivity of $38.73 \mathrm{~S} / \mathrm{cm}$.

2. D-Ppy coating effectively isolated the substrate from corrosive species in ASW, and maintained the passivated state for underlying copper. After $240 \mathrm{~h}$ of immersion in 
ASW, $i_{\text {corr }}$ merely increased to $3.09 \mu \mathrm{A} / \mathrm{cm}^{2}$ for the d-PPy coated sample, which also maintained the relatively high $R_{\mathrm{ct}}$ value of $4.38 \mathrm{k} \Omega \cdot \mathrm{cm}^{2}$. Compact coating architecture was still observed for the d-PPy protected sample.

3. The bonding tendency of $\mathrm{N}$ and $\mathrm{H}$ on the PPy backbone toward the hydroxylation layer on the copper surface might be responsible for the strong adhesion and the subsequent anticorrosion efficacy for copper substrate. Overall, this work may supply a reliable method for the targeted preparation of robust electro-polymerized coatings with favorable interfacial adhesion and anticorrosion properties.

\begin{abstract}
Author Contributions: H.Z. and X.L. equally contributed to this work. Conceptualization, H.H.; methodology, X.L.; software, X.Z.; investigation, H.Z. and X.L.; data curation, H.Z. and X.L.; writingoriginal draft preparation, H.Z.; writing - review and editing, H.H. and X.L. All authors have read and agreed to the published version of the manuscript.
\end{abstract}

Funding: This research was funded by Beijing Municipal Natural Science Foundation, grant number 2192016; National Natural Science Foundation of China, grant number 21606005; Support Project of High-level Teachers in Beijing Municipal Universities in the Period of 13th Five-year Plan, grant number CIT\&TCD201904042 and Opening Project of Material Corrosion and Protection Key Laboratory of Sichuan Province, grant number 2021CL20.

Data Availability Statement: The data presented in this study are available on request from the corresponding author. The data are not publicly available due to privacy.

Conflicts of Interest: The authors declare no conflict of interest.

\title{
References
}

1. Li, X.G.; Zhang, D.W.; Liu, Z.Y.; Li, Z.; Du, C.W.; Dong, C.F. Share corrosion data. Nature 2015, 527, 441-442. [CrossRef] [PubMed]

2. Shi, L.X.; Xiang, L.; Tao, J.Q.; Liu, J.; Chen, Q.; Zhong, Y. Effects of actual marine atmospheric pre-corrosion and pre-fatigue on the fatigue property of 7085 aluminum alloy. Metals 2022, 12, 81. [CrossRef]

3. Fan, B.M.; Liu, Z.N.; Zhao, X.Q.; Liu, H.; Fan, G.H.; Hao, H. Fabrication, characterization and efficient surface protection mechanism of poly(trans-cinnamaldehyde) electropolymerized coatings for EH36 steel in simulated seawater. Colloid Surf. A 2021, 629, 127434. [CrossRef]

4. $\quad$ Li, D.J.; Zhao, X.Q.; Liu, Z.N.; Liu, H.; Fan, B.M.; Yang, B.; Zheng, X.W.; Li, W.Z.; Zou, H.J. Synergetic anticorrosion mechanism of main constituents in Chinese Yam peel for copper in artificial seawater. ACS Omega 2021, 6, 29965-29981. [CrossRef] [PubMed]

5. Khademian, E.; Salehi, E.; Sanaeepur, H.; Galiano, F.; Figoli, A. A Systematic Review on Carbohydrate biopolymers for adsorptive remediation of copper ions from aqueous environments-part A: Classification and modification strategies. Sci. Total Environ. 2020, 738, 139829. [CrossRef]

6. Fan, B.M.; Wei, G.; Hao, H.; Guo, A.; Li, J. Preparation of a ceramic membrane from prevalent natural clay for the purification of phosphate wastewater. Desalin. Water Treat. 2016, 57, 17308-17321. [CrossRef]

7. Garcia-Cabezon, C.; Garcia-Hernandez, C.; Rodriguez-Mendez, M.L.; Martin-Pedrosa, F. A new strategy for corrosion protection of porous stainless steel using polypyrrole films. J. Mater. Sci. Technol. 2020, 37, 85-95. [CrossRef]

8. Saady, A.; Rais, Z.; Benhiba, F.; Salim, R.; Ismaily Alaoui, K.; Arrousse, N.; Elhajjaji, F.; Taleb, M.; Jarmoni, K.; Kandri Rodi, Y.; et al. Chemical, electrochemical, quantum, and surface analysis evaluation on the inhibition performance of novel imidazo[4,5-b] pyridine derivatives against mild steel corrosion. Corros. Sci. 2021, 189, 109621. [CrossRef]

9. Umoren, S.A.; Solomon, M.M. Protective polymeric films for industrial substrates: A critical review on past and recent applications with conducting polymers and polymer composites/nanocomposites. Prog. Mater. Sci. 2019, 104, 380-450. [CrossRef]

10. Chen, Z.H.; Villani, E.; Inagi, S. Recent progress in bipolar electropolymerization methods toward one-dimensional conducting polymer structures. Curr. Opin. Electrochem. 2021, 28, 100702. [CrossRef]

11. Zadeh, M.K.; Yeganeh, M.; Shoushtari, M.T.; Esmaeilkhanian, A. Corrosion performance of polypyrrole-coated metals: A review of perspectives and recent advances. Synth. Metals 2021, 274, 116723. [CrossRef]

12. Menkuer, M.; Ozkazanc, H. Anticorrosive Polypyrrole/zirconium-oxide composite film prepared in oxalic acid and dodecylbenzene sulfonic acid mix electrolyte. Prog. Org. Coat. 2020, 147, 105815. [CrossRef]

13. Nascimento, C.B.; dos Santos, S.L.; Venancio, E.C.; Antunes, R.A. Exploring the relationship between the surface chemistry and the corrosion behavior of electropolymerized polypyrrole films deposited on the surgical ISO 5832-1 stainless steel. Surf. Interface Anal. 2020, 52, 635-644. [CrossRef]

14. Chen, Z.H.; Yang, W.Z.; Xu, B.; Chen, Y.; Qian, M.Q.; Su, X.; Li, Z.H.; Yin, X.S.; Liu, Y. Corrosion protection of carbon steels by

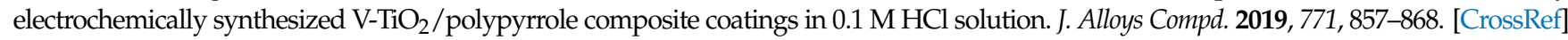

15. Ma, Y.C.; Fan, B.M.; Liu, H.; Fan, G.F.; Hao, H.; Yang, B. Enhanced corrosion inhibition of aniline derivatives electropolymerized coatings on copper: Preparation, characterization and mechanism modeling. Appl. Surf. Sci. 2020, 514, 146086. [CrossRef] 
16. Tharchanaa, S.B.; Priyanka, K.; Preethi, K.; Shanmugavelayutham, G. Facile synthesis of Cu and CuO nanoparticles from copper scrap using plasma arc discharge method and evaluation of antibacterial activity. Mater. Technol. 2021, 36, 97-104. [CrossRef]

17. Wang, M.M.; Fan, B.M.; Wen, B.Y.; Jiang, C. Experimental and theoretical studies on the removal mechanism of formaldehyde from water by mesoporous calcium silicate. Sci. China Technol. Sci. 2020, 63, 2098-2112. [CrossRef]

18. Ma, Y.C.; Zhou, T.T.; Zhu, W.Q.; Fan, B.M.; Liu, H.; Fan, G.F.; Hao, H.; Sun, H.; Yang, B. Understanding the anticorrosive mechanism of a cross-linked supramolecular polymer for mild steel in the condensate water: Comprehensive experimental, molecular docking, and molecular dynamics investigations. J. Mol. Model. 2020, 26, 81. [CrossRef]

19. Liu, H.; Fan, B.M.; Fan, G.F.; Zhao, X.Q.; Liu, Z.N.; Hao, H.; Yang, B. Long-term protective mechanism of poly(Nmethylaniline)/phosphate one-step electropolymerized coatings for copper in $3.5 \% \mathrm{NaCl}$ solution. J. Alloys Compd. 2021, 872, 159752. [CrossRef]

20. Herlem, G.; Picaud, F. Breaking the controversy of the electropolymerization of pyrrole mechanisms by the effective screening medium quantum charged model interface. J. Phys. Chem. A 2021, 125, 1860-1869. [CrossRef]

21. Bonechi, M.; Innocenti, M.; Vanossi, D.; Fontanesi, C. The fundamental and underrated role of the base electrolyte in the polymerization mechanism. The resorcinol case study. J. Phys. Chem. A 2021, 125, 34-42. [CrossRef] [PubMed]

22. Liu, H.; Fan, B.M.; Fan, G.F.; Ma, Y.C.; Hao, H.; Zhang, W. Anti-corrosive mechanism of poly (N-ethylaniline)/sodium silicate electrochemical composites for copper: Correlated experimental and in-silico studies. J. Mater. Sci. Technol. 2021, 72, 202-216. [CrossRef]

23. Golgovici, F.; Cârlan, M.S.; Popescu, A.G.; Anicai, L. Electrochemical Synthesis of Polypyrrole and Polypyrrole-Indomethacin Coatings on Nicr Alloys Involving Deep Eutectic Solvents. Metals 2020, 10, 1130. [CrossRef]

24. Jothi, V.; Adesina, A.Y.; Madhan Kumar, A.; Rahman, M.M.; Nirmal Ram, J.S. Enhancing the biodegradability and surface protective performance of AZ31 mg alloy using polypyrrole/gelatin composite coatings with anodized Mg surface. Surf. Coat. Technol. 2020, 381, 125139. [CrossRef]

25. Garcia-Cabezón, C.; Rodriguez-Mendez, M.L.; Borrás, V.A.; Raquel, B.; Cabello, J.C.R.; Fonseca, A.I.; Martin-Pedrosa, F. Application of plasma electrolytic oxidation coating on powder metallurgy Ti-6Al-4V for dental implants. Metals 2020, 10, 1167. [CrossRef]

26. Ma, Y.C.; Fan, B.M.; Hao, H.; Lu, J.Y.; Feng, Y.H.; Yang, B. Experimental and theoretical studies of action mechanism of an octadecylamine-based molecular assembly on mild steel. Chem. J. Chin. Univ. 2019, 40, 96-107.

27. Fan, B.M.; Ma, Y.C.; Wang, M.M.; Hao, H.; Yang, B.; Lv, J.Y.; Sun, H. Revealing the assembly mechanism of an octadecylamine based supramolecular complex on mild steel in condensate water: Correlative experimental and theoretical studies. J. Mol. Liq. 2019, 292, 111446. [CrossRef]

28. Fan, G.F.; Liu, H.; Fan, B.M.; Ma, Y.C.; Hao, H.; Yang, B. Trazodone as an efficient corrosion inhibitor for carbon steel in acidic and neutral chloride-containing media: Facile synthesis, experimental and theoretical evaluations. J. Mol. Liq. 2020, 311, 113302. [CrossRef]

29. Zhou, Z.Y.; Li, X.; Guo, D.; Shinde, D.B.; Lu, D.W.; Chen, L.; Liu, X.W.; Cao, L.; Aboalsaud, A.M.; Hu, Y.X. Electropolymerization of robust conjugated microporous polymer membranes for rapid solvent transport and narrow molecular sieving. Nat. Commun. 2020, 11, 5323. [CrossRef]

30. Ma, Y.C.; Fan, B.M.; Wang, M.M.; Yang, B.; Hao, H.; Sun, H.; Zhang, H.J. Two-step preparation of trazodone and its corrosion inhibition mechanism for carbon steel. Chem. J. Chin. Univ. 2019, 40, 1706-1716.

31. Asan, G.; Asan, A.; Çelikkan, H. The effect of 2D-MoS 2 doped polypyrrole coatings on brass corrosion. J. Mol. Struct. 2020, 1203, 127318. [CrossRef]

32. Liu, H.; Fan, B.M.; Liu, Z.N.; Zhao, X.Q.; Yang, B.; Zheng, X.W.; Hao, H. Electronic effects on protective mechanism of electropolymerized coatings based on $N$-substituted aniline derivatives for mild steel in saline solution. J. Ind. Eng. Chem. 2022, 106, 297-310. [CrossRef]

33. Meng, S.G.; Liu, Z.N.; Zhao, X.Q.; Fan, B.M.; Liu, H.; Guo, M.; Hao, H. Efficient corrosion inhibition by sugarcane purple rind extract for carbon steel in $\mathrm{HCl}$ solution: Mechanism analyses by experimental and in silico insights. RSC Adv. 2021, 11, 31693-31711. [CrossRef]

34. Obot, I.B.; Onyeachu, I.B. Electrochemical frequency modulation (EFM) technique: Theory and recent practical applications in corrosion research. J. Mol. Liq. 2018, 249, 83-96. [CrossRef]

35. Adeosun, W.A.; Asiri, A.M.; Marwani, H.M. Sensitive determination of 2-nitrophenol using electrochemically deposited polymethyl red film for healthcare and environmental safety. Synth. Metals 2020, 261, 116321. [CrossRef]

36. Martinez, A.L.; Brugnoni, L.I.; Flamini, D.O.; Saidman, S.B. Immobilization of Zn species in a polypyrrole matrix to prevent corrosion and microbial growth on Ti-6Al-4V alloy for biomedical applications. Prog. Org. Coat. 2020, 144, 105650. [CrossRef]

37. Fan, B.M.; Hao, H.; Yang, B.; Li, Y. Insights into the inhibition mechanism of a novel supramolecular complex towards the corrosion of mild steel in the condensate water: Experimental and theoretical studies. Res. Chem. Intermed. 2018, 44, 5711-5736. [CrossRef]

38. Ma, Y.C.; Fan, B.M.; Zhou, T.T.; Hao, H.; Yang, B.; Sun, H. Molecular assembly between weak crosslinking cyclodextrin polymer and trans-cinnamaldehyde for corrosion inhibition towards mild steel in 3.5\% $\mathrm{NaCl}$ solution: Experimental and theoretical studies. Polymers 2019, 11, 635. [CrossRef]

39. Fan, B.M.; Hao, H.; Guo, A.R.; Yang, R.P. Fabrication and evaluation of an attapulgite membrane as the filter for recycling blowdown water from industrial boilers. J. Water Reuse Desal. 2016, 6, 399-412. [CrossRef] 